\title{
Modeling Exchange Rate Volatility using APARCH Models
}

\author{
Carolyn Ogutu ${ }^{1}$, Betuel Canhanga ${ }^{2}$, Pitos Biganda ${ }^{3}$ \\ ${ }^{1}$ School of Mathematics, University of Nairobi, Nairobi, Kenya \\ ${ }^{2}$ Department of Mathematics and Computer Sciences, Eduardo Mondlane University, Mozambique \\ ${ }^{3}$ Department of Mathematics, University of Dar Es Salaam, Tanzania \\ Corresponding authors: betueljesus@gmail.com,canhanga@uem.mz
}

Received: Nov 7, $2017 \quad$ Revised: Feb 5, $2018 \quad$ Accepted: Feb 10, 2018

\begin{abstract}
ARCH (Autoregressive Conditional Heteroskedacity) and GARCH (Generalized Autoregressive Conditional Heteroskedacity) models have been used in forecasting fluctuations in exchange rates, commodities and securities and are appropriate for modeling time series in which there is non-constant variance, and in which the variance at one time period is dependent on the variance at a previous time period. In our paper we deal with APARCH models (Arithmetic Power Autoregressive Conditional Heteroskedasticity) in order to fit into a data series with asymmetric characteristics. We use Kenyan, Tanzanian and Mozambican data and perform the time series analysis and obtain a model that characterize the data set under consideration.
\end{abstract}

Keywords: GARCH, ARCH, APARCH, ARMA

\section{Introduction}

Modeling and forecasting of exchange rate volatility has become a relevant aspect and task in financial markets and economies. In the wake of the global financial crisis, developing countries especially in the sub-Saharan Africa were affected just as much as the developed countries. For instance, Mozambique and Tanzania were at risk because of the significant share of foreign owned banks and their economies dependence on foreign direct investment. Kenya was also affected since during the crisis key indicators such as remittances, tourism and stock prices dropped by $40 \%, 30 \%$ and $40 \%$ respectively [8]. In addition to the global crisis, these three countries have also been mired by political unrest as a result of national elections. It is on this premise that we consider the three economies and study the effects of the global crisis and national elections on the exchange rate volatility.

Volatility of exchange rate returns has gained considerable attention to market participants, investors, and policy makers in order to fully understand the changes and the financial stability of an economy. It is also modeled because it is a measurement of risk for investment and provides essential information for the investors to make decisions. In Mozambique, Tanzania and Kenya, banks as well as other financial institutions play important roles as depositories and provide 
financial instrument for household wealth, maintaining payment systems and vehicles for implementing monetary and fiscal policies for maintaining confidence in the financial sector and hence economic growth [10]. Investments in these three countries is often in foreign exchange instruments and hence the need for accurate modeling and forecasting of volatility.

Generalized Autoregressive Conditional Heteroscedasticity (GARCH) models have been used quite often in recent years, especially in finance. This class of models was introduced by Engle [5]. when he modeled the serial correlation of squared returns by allowing the conditional variance as a function of the past errors and changing time. He did this whilst trying to explain the dynamic of inflation in the United Kingdom. Bollerslev [1] extended Engle's model to have long memory and more flexible lag structure by adding lagged conditional variance to the model as well. These models are specifically designed to capture the volatility clustering of returns but fail to capture the fat-tailed property of the returns. This has led to the need to use non-normal distributions within the extensions of GARCH models. One of such models is APARCH (Arithmetic Power Autoregressive Conditional Heteroscedasticity) model [4]. This model is quite promising since it captures the fat-tails, skewness and leverage effect characteristics of the returns. In the present paper we use APARCH models to capture the asymmetry of the exchange rate returns of the Mozambique Metical, Tanzanian and Kenyan shillings against the United States (US) dollars because most of the foreign transactions occur in US dollars.

The rest of the paper is structured as follows: In section 2, we set out the methodology and model specifications. Further in section 3, we present the empirical results and discussions and finally in section 4 we present the conclusions.

\section{Methodology}

We perform exploratory data analysis to check for any stylized facts in the data set especially stationarity and normality [2]. To check for stationarity, we use the Augmented Dickey Fuller (ADF) test [3]. while to check for normality we use the Jarque-Bera (JB) test [7]. If the data is not stationary, then we perform differencing on the data set until stationarity is achieved. Once, we have achieved stationarity, we model the data using a conditional mean model - ARMA model.

\subsection{ARMA Model}

This model was developed in order to fit data so as to remove the linear dependence in the series and to obtain the residuals which as uncorrelated. Let series $\left\{\mathrm{p}_{t}\right\}$ satisfy ARMA $\left(\mathrm{L}_{1}, \mathrm{~L}_{2}\right)$, then $\left\{\mathrm{p}_{\mathrm{t}}\right\}$ can be described as

$p_{t}=\mu+\sum_{i=1}^{L_{1}} \emptyset_{i} p_{t-1}+\sum_{j=1}^{L_{2}} \varphi_{j} a_{t-j}+a_{t}$

where $\emptyset_{i}$ and $\varphi_{j}$ are parameters and $\mathrm{E}\left[\mathrm{a}_{\mathrm{t}}\right]=0$ and $\operatorname{Var}\left(\mathrm{a}_{\mathrm{t}}\right)=\sigma^{2}$. 


\subsection{GARCH Model}

This model was developed by Bollerslev in 1993 to capture the dynamics of conditional variance. The standard GARCH $\left(\mathrm{L}_{3}, \mathrm{~L}_{4}\right)$ model specification can be expressed as

$$
\begin{array}{ll}
p_{t}=X_{t} \rho+a_{t} & t=1,2, \ldots, T \\
a_{t}=\sigma_{t} z_{t}, \quad z_{t} \backsim N(0,1) & \\
\sigma^{2}=\omega+\sum_{j=1}^{L_{\mathrm{s}}} \beta_{j} \sigma_{t-j}^{2}+\sum_{j=1}^{L_{4}} \alpha_{j} a_{t-j}^{2} .
\end{array}
$$

\subsection{ARMA - GARCH Model}

An ARMA $\left(\mathrm{L}_{1}, \mathrm{~L}_{2}\right)$ - GARCH $\left(\mathrm{L}_{3}, \mathrm{~L}_{4}\right)$ model caters for autocorrelation, volatility clustering and heteroscedasticity. This model is defined as

$$
\begin{aligned}
& p_{t}=\mu+\sum_{i=1}^{L_{1}} \emptyset_{i} p_{t-1}+\sum_{j=1}^{L_{2}} \varphi_{j} a_{t-j}+a_{t} \\
& a_{t}=\sigma_{t} \varepsilon_{t} \varepsilon_{t} \sim N(0,1) \\
& \sigma_{t}^{2}=\alpha_{0}+\sum_{i=1}^{L_{s}} \alpha_{i} a_{t-i}^{2}+\sum_{j=1}^{L_{4}} \beta_{j} \sigma_{t-j}^{2}
\end{aligned}
$$

\subsection{APARCH Model}

To account for the asymmetry in the data, instead of the GARCH models we use the asymmetric power ARCH models - APARCH, introduced by Ding, Granger and Engle [4].

$y_{t}=X_{t} \rho+a_{t} \quad t=1,2, \ldots, T$

$a_{t}=\sigma_{t} z_{t}, \quad z_{t} \backsim N(0,1)$,

then the formula for $\sigma_{t}^{2}$ now becomes

$\sigma_{t}^{\delta}=\alpha_{0}+\sum_{i=1}^{L_{\mathrm{g}}} \alpha_{i}\left(\left|\varepsilon_{t-i}\right|-\gamma_{i} \varepsilon_{t-i}\right)^{\delta}+\sum_{j=1}^{L_{4}} \beta_{j} \sigma_{t-j}^{\delta}$

where $\delta>0$ and the leverage parameters $-1<\gamma_{i}<1$. A positive $\gamma_{i}$ means negative information has stronger impact than the positive information on the return volatility. 


\subsection{Distributional Assumptions}

Research shows that most financial time series deviate from the normality assumption. It is therefore of paramount importance to us to model our data under distributional assumptions that will capture the excess kurtosis and the skewness. In our paper, the normal distribution is used as a benchmark and student-t is further assumed to cater for the normal distribution's shortfalls. We estimate the parameters using maximum likelihood estimation method.

\subsubsection{Normal Distribution}

If the error term is normal, then the log-likelihood function of the standard normal distribution is given as

$L_{T}=\ln \prod_{t} \frac{1}{\sqrt{2 \pi \sigma_{t}^{2}}} e^{\frac{a_{t}^{\tilde{z}}}{\sigma^{2}}}=-\frac{1}{2} \sum_{t=1}^{T}\left\{\ln (2 \pi)+\ln \left(\sigma_{t}^{2}\right)+z_{t}^{2}\right\}$

where $z_{t}=\frac{a_{t}}{\sigma_{t}}$ is independent and identically distributed with mean 0 and variance $1, \mathrm{~T}$ is the number of observations with regards to the returns series.

\subsubsection{Student-t Distribution}

If error term follows student-t then since it is symmetric at zero the log-likelihood function is of the form

$L_{T}=T\left\{\ln \left[\Gamma\left(\frac{v+1}{2}\right)\right]-\ln \left[\Gamma\left(\frac{v}{2}\right)\right]-\frac{1}{2} \ln [\pi(v-2)]\right\}-\frac{1}{2} \sum_{t=1}^{T}\left[\ln \left(\sigma_{t}^{2}\right)+(1+v) \ln \left(1+\frac{z_{t}^{2}}{v-2}\right)\right]$

where the shape parameter is $2<v \leq \infty$ and $\Gamma($.$) is the gamma function.$
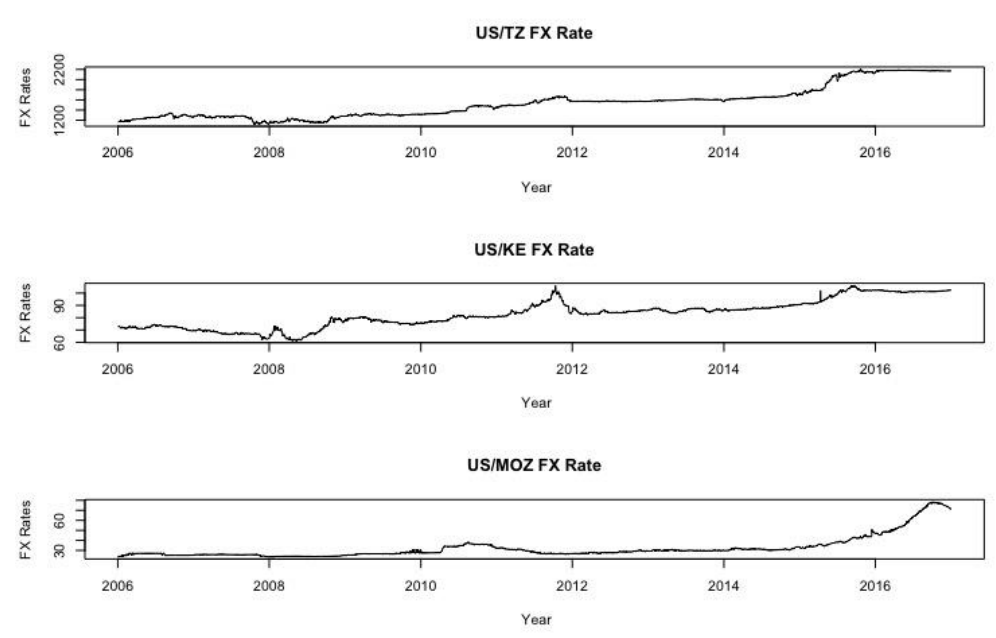

Fig. 1: Time series plots of mean exchange rate data from January 2006 to December 2016 of the three currencies against the dollar. 

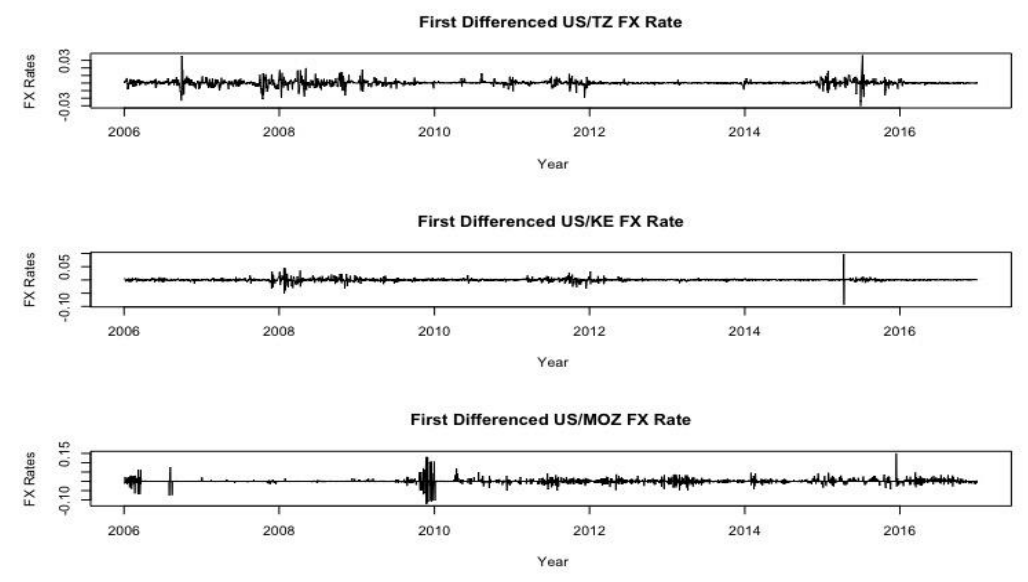

Fig. 2: First difference of mean exchange rate data from January 2006 to December 2016 of the three currencies against the dollar.

\section{Data Analysis and Results}

This paper investigates the patterns of return series for 3 exchange rates against the dollar, that is, Kenya, Mozambique and Tanzania, for the 10 year period starting January 1, 2006 until December 31, 2016, downloaded from https://www.oanda.com/fx-for-business/historical-rates accessed on 25 February, 2017. Fig. 1 presents the time series of the mean exchange data from January 2006 to December 2016 in the 3 countries, against the dollar. And in the Fig. 2 we produce the first difference of the data's in order to stationarize them. We start by giving some descriptive statistics for the three datasets. This is shown in Table 1

Table 1: Summary statistics for exchange rate returns from the three countries against the US dollar

\begin{tabular}{|l|l|l|l|}
\hline & $\begin{array}{l}\text { Tanzania } \\
\text { USD/TSHS }\end{array}$ & $\begin{array}{l}\text { Kenya } \\
\text { USD/KSHS }\end{array}$ & $\begin{array}{l}\text { Mozambique } \\
\text { USD/MZN }\end{array}$ \\
\hline Mean & 0.000229 & 0.000125 & 0.000378 \\
\hline Median & 0.000114 & 0.00 & 0.00 \\
\hline Variance & 0.000012 & 0.000029 & 0.00016 \\
\hline Standard Deviation & 0.003477 & 0.005389 & 0.01264 \\
\hline Minimum & -0.030184 & -0.0943 & -0.1215 \\
\hline Maximum & 0.036547 & 0.09648 & 0.1502 \\
\hline Skewness & 0.2292 & 0.0813 & 0.7448 \\
\hline Kurtosis & 19.0015 & 82.505 & 39.93 \\
\hline Jarque Bera Test & $\begin{array}{l}40938 \\
(<2.2 \mathrm{e}-16)\end{array}$ & $\begin{array}{l}789380 \\
(<2.2 \mathrm{e}-16)\end{array}$ & $\begin{array}{l}191020 \\
(<2.2 \mathrm{e}-16)\end{array}$ \\
\hline
\end{tabular}


From Table 1 we note the following, first, all the three exchange rate returns show daily positive mean. Also, we can see that all the datasets exhibit positive skewness showing that the return series are flatter to the right. In addition, the kurtosis values show that the return series are leptokurtic. Finally, from the results of the Jarque Bera test find that the null hypothesis of normality has to be rejected for all the three return series.

We wrote an $\mathrm{R}$ function to select the best ARMA model based on the Akaike Information Criterion (AIC) that is, selecting the ARMA model with the lowest AIC, see the results shown in Table 1. AIC measures the goodness of fit or uncertainty for the ranges of values of the data. AIC is calculated as

$$
A I C=n \cdot \ln \left(\frac{S S E}{n}\right)+2 k
$$

where SSE is the sum of squared errors, $n$ is the number of observations and $k$ is the number of independent variables [11]. So from Table 2, we see that ARMA $(2,2)$ has the lowest AIC.

Table 2: Various ARMA orders with their corresponding AIC values. The values in this table are estimated using the new R function we wrote to calculate ARMA.

\begin{tabular}{|l|l|l|l|l|l|l|l|l|l|}
\hline $\begin{array}{l}\text { Order } \\
\text { Data }\end{array}$ & $\mathbf{( 0 , 0 )}$ & $\mathbf{( 0 , 1 )}$ & $\mathbf{( 0 , 2 )}$ & $\mathbf{( 1 , 0 )}$ & $\mathbf{( 1 , 1 )}$ & $\mathbf{( 1 , 2 )}$ & $\mathbf{( 2 , 0 )}$ & $\mathbf{( 2 , 1 )}$ & $\mathbf{( 2 , 2 )}$ \\
\hline TZ & -23033.96 & -23269.43 & -23356.43 & -23322.65 & -23322.86 & -23355.36 & -23324.66 & -23339.46 & $\mathbf{- 2 3 3 6 3 . 2 3}$ \\
\hline KE & -21142.07 & -21152.9 & -21167.09 & -21150.74 & -21157.65 & -21165.95 & -21170.23 & -21168.31 & $-\mathbf{2 1 1 7 4 . 1 3}$ \\
\hline MOZ & -16921.41 & -17380.92 & -17378.94 & -17318.38 & -17378.95 & -17381.38 & -17352.36 & -17379.71 & $-\mathbf{1 7 3 8 9 . 1 6}$ \\
\hline
\end{tabular}

We compared our results with those of the auto.arima command in zoo package, see Table 3.

Table 3: Comparison of results from fitting conditional mean model (ARMA) using auto.arima from the zoo package and our own arma function.

\begin{tabular}{|l|l|l|}
\hline Data & ARMA (New Function) & ARMA (auto.arima) \\
\hline USD/TSHS & $\operatorname{ARMA}(2,2)$ & $\operatorname{ARMA}(2,2)$ \\
\hline USD/KSHS & $\operatorname{ARMA}(2,2)$ & $\operatorname{ARMA}(2,2)$ \\
\hline USD/MZN & $\operatorname{ARMA}(2,2)$ & $\operatorname{ARMA}(2,2)$ \\
\hline
\end{tabular}

Having the suitable model, we fit the ARMA $(2,2)$ model to our data and we then analyzed the residuals of the said models for any ARCH effects. We do this by performing the McLeod Li test [9] on the residuals of the selected ARMA models. In the McLeod Li test, the null hypothesis is that there are no ARCH effects. 

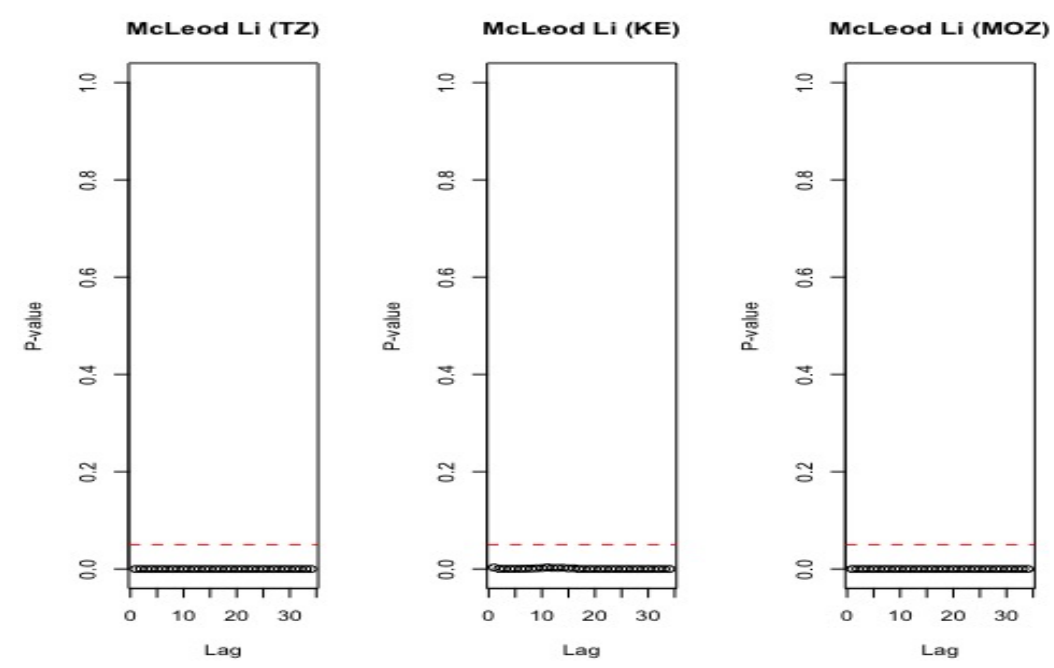

Fig. 3: Graphical results of McLeod Li test for ARCH effects for the three exchange rate returns.

The null of no ARCH effects is rejected in all three cases.

The results of our test showed that for all the exchange rates for 40 lags, the p-values are less than the level of significance and therefore the null is rejected, which implies that the returns have ARCH effects. We follow-up by fitting GARCH $\left(\mathrm{L}_{3}, \mathrm{~L}_{4}\right)$ models on the residuals of the conditional mean model. We start with GARCH $(1,1)$, since it is the simplest and research has shown that it is difficult to find a model that performs better than it [6]. We started with the case where the conditional distribution is normal.
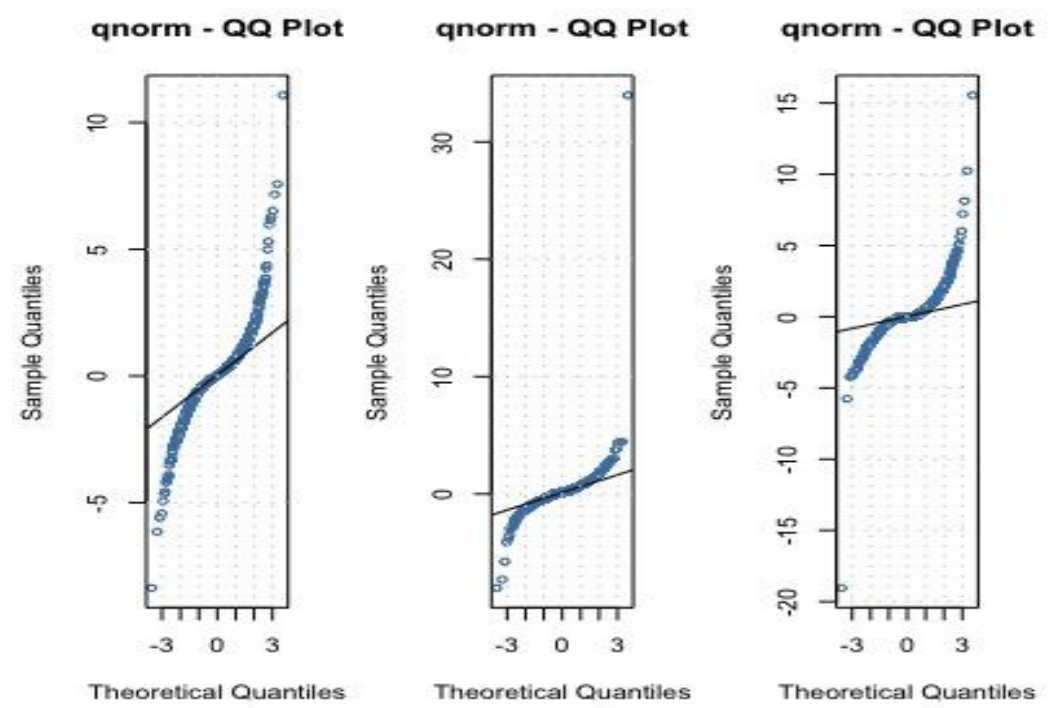

Fig. 4: QQ Plot of the standardized residuals for the $\operatorname{ARMA}(2,2)-\operatorname{GARCH}(1,1)$ fit with conditional distribution as normal for the three currencies - Tanzania on the left, Kenya in the middle and Mozambique on the right. 

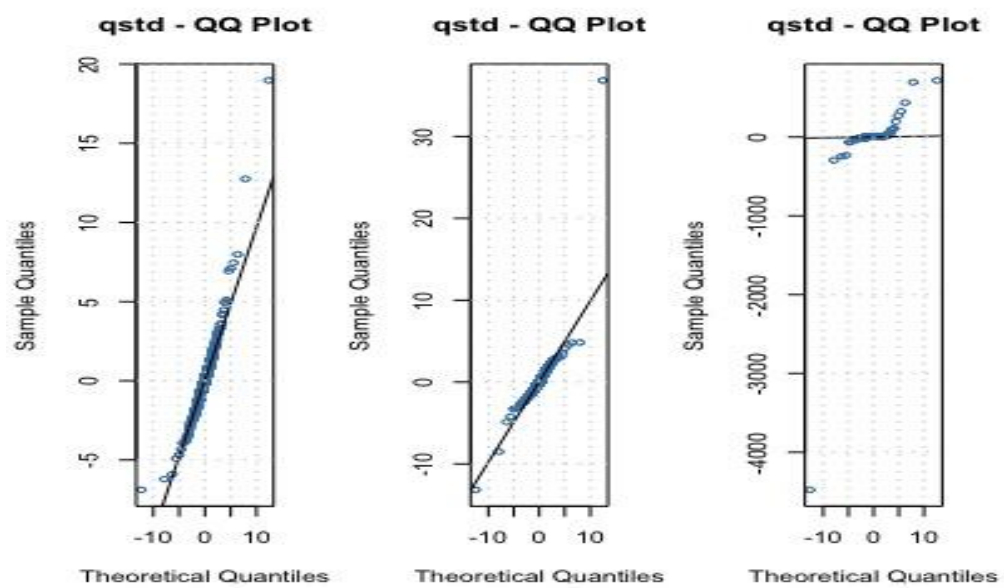

Fig. 5: QQ Plot of the standardized residuals for the $\operatorname{ARMA}(2,2)-\operatorname{GARCH}(1,1)$ fit with conditional distribution as student-t for the three currencies - Tanzania on the left, Kenya in the middle and Mozambique on the right.

For all the three currencies we notice that the $\operatorname{ARMA}(2,2)-\operatorname{GARCH}(1,1)$ with normal conditional distribution is not a good fit since only approximately $60 \%$ of the residuals lie on the QQ line, Fig. 4. This causes us to change our conditional distribution to student-t which as we can see from Fig. 5 gives an improvement from the previous model. From Fig. 5, we now see that approximately $85 \%$ of the residuals lie on the QQ line. Table 4 shows the results of the maximum likelihood estimation of the parameters once we fit the ARMA $(2,2)-\operatorname{GARCH}(1,1)$ with normal and student-t conditional distributions.

Table 4: Parameter estimation results for $\operatorname{ARMA}(2,2)-\operatorname{GARCH}(1,1)$ models with normal and student-t distributions and their corresponding p-values.

\begin{tabular}{|c|c|c|c|c|c|c|}
\hline & $\begin{array}{l}\text { Conditional } \\
\text { Distribution }\end{array}$ & Mu & Omega & Alpha1 & Beta1 & Shape \\
\hline \multirow[t]{2}{*}{ USD/TSHS } & Normal & $\begin{array}{l}8.089 \mathrm{e}-05 \\
(3.06 \mathrm{e}-05)\end{array}$ & $\begin{array}{l}5.1853 \mathrm{e}-08 \\
(<2.2 \mathrm{e}-16)\end{array}$ & $\begin{array}{l}3.189 \mathrm{e}-01 \\
(<2.2 \mathrm{e}-16)\end{array}$ & $\begin{array}{l}7.634 \mathrm{e}-01 \\
(<2.2 \mathrm{e}-16)\end{array}$ & - \\
\hline & Student-t & $\begin{array}{l}6.4511 \mathrm{e}-05 \\
(8.44 \mathrm{e}-15)\end{array}$ & $\begin{array}{l}2.153 \mathrm{e}-08 \\
(4.63 \mathrm{e}-06)\end{array}$ & $\begin{array}{l}1.000 \\
(1.89 \mathrm{e}-11)\end{array}$ & $\begin{array}{l}6.415 \mathrm{e}-01 \\
(<2.2 \mathrm{e}-16)\end{array}$ & $\begin{array}{l}2.446 \mathrm{e}+00 \\
(<2.2 \mathrm{e}-16)\end{array}$ \\
\hline \multirow[t]{2}{*}{ USD/KSHS } & Normal & $\begin{array}{l}-3.299 \mathrm{e}-04 \\
(<2 \mathrm{e}-16)\end{array}$ & $\begin{array}{l}4.735 \mathrm{e}-09 \\
(0.806)\end{array}$ & $\begin{array}{l}\begin{array}{l}5.273 \mathrm{e}-01 \\
(<2 \mathrm{e}-16)\end{array} \\
\end{array}$ & $\begin{array}{l}7.980 \mathrm{e}-01 \\
(<2 \mathrm{e}-16)\end{array}$ & - \\
\hline & Student- $t$ & $\begin{array}{l}5.5585 \mathrm{e}-05 \\
(0.01484)\end{array}$ & $\begin{array}{l}1.435 \mathrm{e}-07 \\
(0.03666)\end{array}$ & $\begin{array}{l}7.112 \mathrm{e}-01 \\
(0.00501)\end{array}$ & $\begin{array}{l}7.360 \mathrm{e}-01 \\
(<2 \mathrm{e}-16)\end{array}$ & $\begin{array}{l}2.425 \mathrm{e}+00 \\
(<2 \mathrm{e}-16)\end{array}$ \\
\hline \multirow[t]{2}{*}{ USD/MZN } & Normal & $\begin{array}{l}2.7760 \mathrm{e}-04 \\
(0.0221)\end{array}$ & $\begin{array}{l}1.299 \mathrm{e}-06 \\
(<2 \mathrm{e}-16)\end{array}$ & $\begin{array}{l}8.313 \mathrm{e}-02 \\
(<2 \mathrm{e}-16)\end{array}$ & $\begin{array}{l}9.148 \mathrm{e}-01 \\
(<2 \mathrm{e}-16)\end{array}$ & - \\
\hline & Student-t & $\begin{array}{l}1.7216 \mathrm{e}-07 \\
(0.878)\end{array}$ & $\begin{array}{l}1.354 \mathrm{e}-10 \\
(0.987)\end{array}$ & $\begin{array}{l}1.000 \\
(<2 \mathrm{e}-16)\end{array}$ & $\begin{array}{l}5.120 \mathrm{e}-01 \\
(<2 \mathrm{e}-16)\end{array}$ & $\begin{array}{l}2.311 \mathrm{e}+00 \\
(<2 \mathrm{e}-16)\end{array}$ \\
\hline
\end{tabular}


All the parameters are significant except for the coefficients of omega in the USD/KSHS with normal distribution and mu and omega in the case of USD/MZN with student-t distribution. When we consider the normal distributional assumption, the estimates $\left(\alpha_{i}+\beta_{j}\right)$ are greater than 1 for USD/TSHS and USD/KSHS implying that the volatility rate model is strictly stationary while that for USD/MZN is less than 1, which indicates that the model is well fitted. In the case of student-t distributional assumption, all the estimates are greater than 1 .

When we fit the $\operatorname{ARMA}(2,2)-\operatorname{APARCH}(1,1)$ model to our data, we get the results shown in Fig. 6. For the Tanzanian and the Kenya datasets, one may not be able to distinguish from the QQ plots in Fig. 5 and Fig. 6. On the other hand, for Mozambican dataset, we can clearly see that $95 \%$ of the residuals now lie on the QQ line. This goes to show that the $\operatorname{ARMA}(2,2)-$ $\operatorname{APARCH}(1,1)$ with student-t conditional distribution is a good fit for the data. The estimates for the parameters are shown in Table 5. From the table, in the case of USD/TSHS and USD/KSHS, all the parameters are significant except the estimation for gamma. In this case, gamma is negative which means that negative shock results to higher next period conditional variance than positive shocks of the same sign. That is, bad news affects volatility more than good news. Further, for USD/MZN, parameter estimates for mu and omega are insignificant, but the estimation for the leverage effect is positive.

Table 5: Parameter estimation results for $\operatorname{ARMA}(2,2)-\operatorname{APARCH}(1,1)$ models with student-t distributions and their corresponding p-values.

\begin{tabular}{|l|l|l|l|}
\hline & USD/TSHS & USD/KSHS & USD/MZN \\
\hline Mu & $6.445 \mathrm{e}-05$ & $5.077 \mathrm{e}-05$ & $-3.911 \mathrm{e}-08$ \\
& $(2.13 \mathrm{e}-14)$ & $(0.004913)$ & $(0.969)$ \\
\hline Omega & $7.437 \mathrm{e}-06$ & $3.978 \mathrm{e}-04$ & $2.488 \mathrm{e}-05$ \\
& $(0.012)$ & $(0.000475)$ & $(0.4987)$ \\
\hline Alpha1 & 1.000 & $3.040 \mathrm{e}-01$ & 1.000 \\
& $(2,39 \mathrm{e}-06)$ & $(8.75 \mathrm{e}-08)$ & $(<2 \mathrm{e}-16)$ \\
\hline Gamma1 & $-9.182 \mathrm{e}-03$ & $-7.471 \mathrm{e}-02$ & $9.041 \mathrm{e}-02$ \\
& $(0.806)$ & $(0.18469)$ & $(0.0106)$ \\
\hline Beta1 & $6.725 \mathrm{e}-01$ & $8.206 \mathrm{e}-01$ & $5.989 \mathrm{e}-01$ \\
& $(<2 \mathrm{e}-16)$ & $(<2 \mathrm{e}-16)$ & $(<2 \mathrm{e}-16)$ \\
\hline Delta & 1.262 & $7.619 \mathrm{e}-01$ & $5.642 \mathrm{e}-01$ \\
& $(2.22 \mathrm{e}-15)$ & $(1.64 \mathrm{e}-14)$ & $(<2 \mathrm{e}-16)$ \\
\hline Shape & 2.242 & 2.398 & 2.062 \\
& $(<2 \mathrm{e}-16)$ & $(<2 \mathrm{e}-16)$ & $(<2 \mathrm{e}-16)$ \\
\hline
\end{tabular}



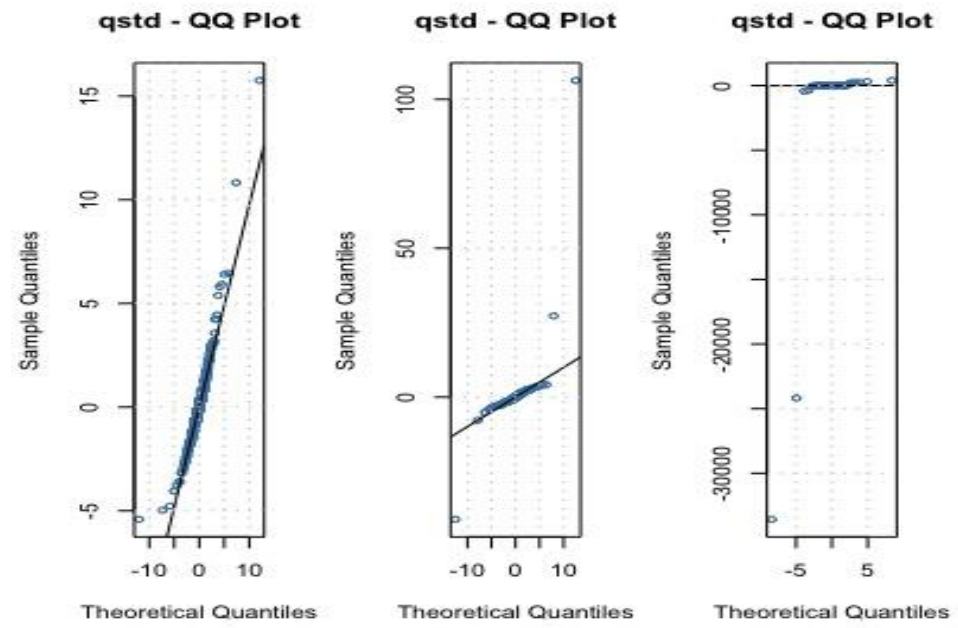

Fig. 6: QQ Plot of the standardized residuals for the $\operatorname{ARMA}(2,2)-\operatorname{APARCH}(1,1)$ fit with conditional distribution as student-t for the three currencies - Tanzania on the left, Kenya in the middle and Mozambique on the right.

\section{Conclusion}

Research shows the importance of exchange rate volatility modeling to investors, academics and policy makers alike. This paper is an addition to the existing literature for volatility modeling using the models ARMA, GARCH and APARCH with normal and student-t distributional assumptions for Tanzania, Kenya and Mozambique exchange rates against the dollar. We found that ARMA $(2,2)$ - APARCH $(1,1)$ with student-t conditional distribution is appropriate for modeling the 3 exchange rates. However, the sum of the parameters alpha and beta for USD/MZN under normal distributional assumption shows that the ARMA $(2,2)-\operatorname{GARCH}(1,1)$ is a good enough model. This result is however negated by the plot of the residuals, which clearly show that the return residuals deviate from normality. In addition the parameter estimates for gamma for USD/TSHS and USD/KSHS are negative showing that bad news affects the volatility more. From our modeling however, these values are insignificant. This would form the basis for future research. Application of models with fractional integration that allow for better capture of the return dynamics should be used to model the return series for these three exchange rate return series.

\section{References}

[1] Bollerslev T (1986), Generalized Autoregressive Conditional Heteroscedasticity, Journal of Economics, $31: 307$ - 327.

[2] Cont R (2001), Empirical Properties of Assets Returns: Stylized Facts and Statistical Issues. Quantitative Finance, 1 : 223 - 236.

[3] Dickey DA and Fuller WA (1979), Distribution of the Estimators for Autoregressive Time Series with a Unit Root. Journal of the American Statistical Association, 74 : 427 - 431. 
[4] Ding Z, Granger CWJ and Engle RF (1993), A long Memory Property of Stock Market Returns and a New Model, Journal of Empirical Finance, 1 : 83 - 106.

[5] Engle RF (1982), Autoregressive Conditional Heteroscedasticity with estimates of the variance of united Kingdom Inflation. Econometrica, 50 : 987 - 1007.

[6] Hansen P and Lunde A (2004), A Forecast Comparison of Volatility Models: Does Anything Beat a GARCH(1,1)? Journal of Applied Econometrics, 20(7) : $873-889$.

[7] Jarque CM and Bera AK (1987), A Test for Normality of Observations and Regression Residuals. International Statistical Review, 55 : 163 - 172.

[8] Massa I and Willem te Velde D (2008), The Global Financial Crisis: will successful African countries be affected? Research paper, Overseas Development Institute, $1-28$.

[9] McLeod AI and Li WK (1983), Diagnostic checking ARMA time series models using squared residual autocorrelations. Journal of Time Series Analysis, $4: 269$ - 273.

[10] Thorlie MA, Song L, Wang X and Amin M (2014), Modeling Exchange Rate Volatility Using Asymmetric GARCH Models (Evidence from Sierra Leone), International Journal of Science and Research, 3(11) : $1206-1214$.

[11] Tsay RS (2010), Analysis of Financial Time Series, $3^{\text {rd }}$ edition, John Wiley \& Sons, Inc, Hoboken. 